\title{
ALUNOS HAITIANOS, A BUSCA DE UM SONHO (IM)POSSÍVEL: A REALIDADE VIVIDA POR CRIANÇAS MIGRANTES NA AVALIAÇÃO ESCOLAR
}

\author{
IVONE JESUS AlEXANDRE \\ Paulo Alberto dos Santos Vielra \\ Universidade do Estado de Mato Grosso (UNEMAT), Sinop, Mato Grosso, Brasil
}

\begin{abstract}
Resumo: Este texto tem por objetivo discutir sobre a forma que os alunos haitianos são submetidos aos processos de avaliação escolar internos e externos, além das práticas de avaliação dos professores em duas escolas públicas de Sinop/MT. Os dados apresentados neste texto são de abordagem etnográfica e foram gerados a partir de observações em sala de aula, nas turmas dos anos iniciais de escolas públicas, que receberam alunos migrantes haitianos no período de 2015-2016, além de entrevista com a gestora de uma dessas duas escolas. Constatamos que os processos avaliativos são padronizados e afetam o desempenho e êxito escolar dos alunos migrantes, e os professores não foram preparados para trabalhar com a diversidade e a diferença, os conhecimentos e as aprendizagens desses alunos.
\end{abstract}

Palavras-chave: Alunos Haitianos. Cotidiano Escolar. Avaliação.

INTRODUÇÃO

Os estudos sobre a diversidade e diferença na sociedade informam que a escola ainda é centrada em um modelo hegemônico de ser humano: homem, branco, heterossexual e cristão (MAIO, 2020; ABRAMOWICZ et al, 2011; CANDAU, 2008). Esse padrão normativo não trata, de forma igual, as pessoas que estão fora desses padrões, pois elas são percebidas, muitas vezes, como "diferentes", "anormais", "estranhas" e "exóticas".

Esse pensamento gera desigualdade social e educacional. Tânia Muller (2015), por exemplo, afirma que essas desigualdades podem ser superadas ao se promover uma educação cidadã, inclusiva e emancipadora. Nesse sentido, é preciso garantir acesso de qualidade e permanência escolar aos grupos excluídos, além da inserção no currículo escolar de debates que envolvam raça', etnia, gênero e sexualidade, pois só assim poderemos romper com o racismo, xenofobia, machismo, misoginia, homofobia e transfobia na sociedade. Trabalhar esses temas ainda é um enorme desafio para a escola e demais instituições da sociedade.

Uma educação baseada nos direitos, dignidade e cidadania, que valoriza a diversidade cultural e a subjetividade humana, começou a ser defendida no final de 1980. Pesquisadores (LIONCO e DINIZ, 2009; ALTMANN, 2001) afirmam que os Parâmetros Curriculares Nacionais (PCNs), elaborados para o Ensino Básico em 1995, tiveram como um dos temas a "pluralidade cultural", no entanto, a abordagem relacionada à sexualidade foi apontada como superficial. Mas, mesmo assim, essa 
iniciativa foi considerada um divisor importante nas propostas e currículos de temas voltadas para a diversidade e diferenças no âmbito escolar. Com isso, novos programas e propostas aconteceram a partir do ano 2000, além da intensa participação dos movimentos organizados que defendiam essas pautas, até porque foram os governantes com ideias progressistas que chegaram ao poder em quase todo o mundo naquele momento.

As desigualdades são históricas no Brasil. Há um aumento progressivo da violência contra a população negra, as sociedades indígenas, as mulheres e as pessoas LGBTQIA (lésbicas, gays, bissexuais, travestis, transexuais, transgêneros, queers, questionadoras, bigêneros, assexuadas e intersexos) (MAIO, OLIVEIRA e PEIXOTO, 2020). Isso pode ser alterado quando as pautas da diversidade e diferença na escola ultrapassarem a perspectiva multicultural e o trabalho pedagógico considerar as relações de poder que afetam esses grupos.

É nesse contexto que os migrantes ${ }^{2}$ haitianos chegaram ao Brasil a partir de 2010, quando um terremoto devastou o Haiti e intensificou o fluxo migratório. O motivo de escolherem o país, o estado de Mato Grosso, especificamente a cidade de Sinop, ocorreu em função do mercado de trabalho. A cidade é uma das que mais se desenvolvem no estado, e o governo local se empenha em fazer uma divulgação midiática nacional da cidade como próspera, em constante desenvolvimento, que não se altera mesmo com a crise econômica e a pandemia da COVID-19. Sinop tem um projeto de colonização ufanista desde a sua fundação, uma imagem de cidade desenvolvida e rica. A pobreza e diversidade são periféricas e escamoteadas pela mesma mídia que enfoca a opulência de Sinop.

Neste texto, utilizamos os dados da tese $A$ presença das crianças migrantes haitianas nas escolas de SINOP/MT: o que elas visibilizam da escola? ${ }^{3}$ para refletirmos sobre os processos de avaliação internos e externos, além das práticas de avaliação adotadas pelos professores das salas de aula que receberam alunos migrantes. A pesquisadora fez uma análise do cotidiano escolar de 4 alunos migrantes haitianos nas escolas em Sinop e dos processos de avaliação externos e internos a que esses alunos foram submetidos, e que muitas vezes não consideraram sua condição de recémchegados ao país, falarem outra língua, terem uma outra cultura.

A geração dos dados utilizada por Alexandre (2019) foi de base etnográfica, com observações em salas de aula que receberam quatro alunos migrantes do Haiti, dois estudavam na Educação Infantil e dois na escola do Ensino Fundamental. Também apresentamos dados de uma entrevista realizada com uma das gestoras e colaboradora da pesquisa. Alexandre (2019) identificou seus colaboradores por nomes fictícios no intuito de preservar suas identidades, também obedeceu aos critérios éticos com o assentimento e consentimento de todos os envolvidos em sua pesquisa. A pesquisadora realizou as observações no ano de 2016, os exemplos descritos nesse texto ocorreram no ensino fundamental e serviram ao nosso propósito de discussão para este artigo, ou seja, discutir sobre a forma que os alunos haitianos são submetidos aos processos de avaliação escolar internos e externos, além das práticas de avaliação dos professores, em duas escolas públicas de Sinop/MT. 
ALEXANDRE, I. J.; VIEIRA, P. A. dos S

\section{CONTRIBUIÇÕES TEÓRICAS SOBRE A DIVERSIDADE E DIFERENÇA}

Para pensar e refletir sobre a forma como as diferenças são percebidas em nossas instituições e sociedade brasileira, reporto ao artigo Que negro é esse na cultura negra?, de Stuart Hall (2003), que analisa, a partir de um questionamento sobre o momento que se coloca em questão a cultura popular nos Estados Unidos da América (EUA), ou seja, a cultura negra. Para dissertar sobre o assunto, menciono Cornel West (1990), que propõe três eixos explicativos para esse momento: o primeiro é o deslocamento dos modelos europeus de alta cultura, da Europa enquanto sujeito universal da cultura e da própria cultura; o segundo eixo é o surgimento dos EUA como potência mundial e, consequentemente, como centro de produção e circulação global de cultura; e o terceiro eixo é a descolonização do Terceiro Mundo, marcado culturalmente pela emergência das sensibilidades descolonizadas.

Stuart Hall (2003) complementa essas explicações acrescendo qualificações para lembrar as ambiguidades desse deslocamento da Europa para a América. No caso dos EUA, a relação com a alta costura europeia e a ambiguidade da relação dos americanos com suas próprias hierarquias étnicas dentro do País, enquanto a Europa ocidental não tem ou não reconhece uma composição étnica em suas raízes, fizeram com que os americanos tivessem uma série de etnicidades, além de um processo de hierarquização entre elas que justificam as políticas culturais no País na tentativa de romper com essas hierarquias. No entanto, para Hall (2003), mesmo com essas iniciativas, a cultura popular americana, nesses processos de deslocamentos, silenciou e não reconheceu a tradição vernácula da cultura popular negra americana. Assim, a natureza do período de globalização cultural colocou os negros numa relação ambígua tanto no pós-modernismo quanto no alto modernismo, sem desconsiderar, é claro, essa profunda ambivalência e a fascinação do pós-modernismo pelas diferenças sexuais, raciais, culturais e étnicas sem, contudo, promover mudanças estruturais de fato em sua representação e identidade nacional. O pesquisador afirma que, por mais que ocorreram mudanças em relação às questões étnicas e raciais no plano cultural da sociedade americana, a cultura afro-americana ainda continua tendo pouca visibilidade e, quando tem, é superficial e mantém as desigualdades. Embora a agenda da diversidade seja uma agenda política em voga, o discurso presente na sociedade não produz mudanças na maneira de como se vê e percebe a diversidade cultural, na verdade, são diferenças que não fazem nenhuma diferença (HALL, 2003), pois mantêm intactas as desigualdades étnicas raciais.

Por mais que as políticas culturais sejam recentes e ancoradas nos sentidos e significados étnicos da população negra, indígena e branca, isso também ocorre no Brasil, pois as culturas não brancas ainda possuem papel marginal na sociedade. $\mathrm{Na}$ visão de Silvério e Trinidad (2012, p.165), isso ocorre porque a cultura nacional é criada a partir do discurso e significados que são produzidos sobre o "nós" e os "outros", tendo como referência a ideia de nação na formação de identidades. "Estes significados estão contidos nas histórias que são contadas sobre ela, nas memórias que conectam seu presente com seu passado, e nas imagens que são construídas a propósito das nações" (SILVÉRIO; TRINIDAD, 2012, p.165) e que ainda estão diretamente relacionadas ao conceito europeu, ou seja, um modelo que não considera as diferenças étnicas e raciais. 
Isso explica a forma como os migrantes haitianos são percebidos em relação à sua cor, sua cultura e sua origem geográfica.

Podemos buscar alterar essa percepção mudando as narrativas nas escolas, enfocando e visibilizando acontecimentos que sirvam de exemplo de histórias que não são contadas, como, por exemplo, o caso da insurreição do Haiti contra a França, a do Brasil, considerado pelo enfoque dos negros e grupos indígenas. Enfim, diferentes narrativas para pensar a superação dos preconceitos em relação à diversidade humana.

[...] a diversidade tem um caráter universal, pois é uma síntese que totaliza as diferenças, ou seja, as diferenças e as diversidades se configuram como cultura que, por esta via, podem então ser trocadas. Uma das problemáticas decorrentes é que a cultura acaba perdendo sua matriz singular e torna-se um conceito universal, como o biológico. Propostas como a criação de currículos comuns, buscando o que é comum entre as culturas, são correntes no campo educacional. Ao fazer isso, há um processo de tornar estas culturas componentes de uma universalidade, supondo-se possível retirar a estratificação que o poder opera, ou supor que não há relações de poder. É possível perceber nestas concepções, exemplos da junção dos termos diferenças e/ou diversidades como podendo ser compreendidas, trocadas, pactuadas ou re-pactuadas. O mais importante é que há a ideia de que é possível com o nosso cardápio de sentidos compreender todas as diferenças (ABRAMOWICZ et al., 2011, p. 92).

Abramowicz et al. (2011) afirmam que, desde o ano de 1970, o tema da diversidade é foco das discussões no campo educacional. O termo diversidade é considerado uma categoria global e um conceito universal. Para as pesquisadoras, esse conceito tem sido usado indiscriminadamente nos debates e como sinônimo de todas as diversidades. Esse trato serve para explorar o conceito e esvaziar o sentido político, social e amainar as relações sociais.

Aplicado ao currículo nacional, o conceito de diversidade não pode ser apenas um jargão, porque incorporar esse conceito sem fundamentá-lo teoricamente, ou apenas como um conteúdo curricular ou tema transversal, significa esvaziá-lo e reduzi-lo à retórica política, que desconsidera e negligencia questões sociais, econômicas e culturais prementes existentes no cerne desse conceito, porque refletem a luta em promoção de direitos e chances igualitárias para todos os membros da sociedade, independentemente de sua origem, raça, gênero, posição social, renda, orientação sexual, papel social, condição física, cognitiva ou intelectiva, motora, neurológica, sensorial, etc. (FERREIRA, 2015, p. ?).

Louro (2008) e Gomes (2017), quando abordam o conceito da diversidade e diferença em seus estudos com enfoque nas categorias de gênero, raça, etnia e 
sexualidade, afirmam que são construções sociais, históricas, culturais, políticas e econômicas, além de se realizarem no contexto das relações de poder.

Para Woodward (2014), a produção da diferença é realizada por oposições binárias e estas podem ser construídas negativamente por meio da exclusão e marginalização daqueles definidos como os "outros", os "forasteiros", mas também pode ser celebrada como fonte de diversidade, heterogeneidade e hibridismo na sociedade.

\begin{abstract}
A utilização dos termos diversidade e diferença de forma indiscriminada neste período sugere que o processo denominado de ascensão da diversidade é um dos efeitos das lutas sociais realizadas no âmbito dos movimentos sociais, no entanto, traz à tona também as discussões de distintas perspectivas teóricas que se ocupam dessa temática, de mudanças da matriz de políticas públicas, em como compatibilizar nas políticas públicas as exigências de respeito à diferença reivindicadas por grupos sociais sem restringir-se ao relativismo cultural. Ao mesmo tempo, essas distintas perspectivas teóricas atribuem diferentes significados e possibilidades à ideia de diversidade e diferença (ABRAMOWICZ et al., 2011, p. 86).
\end{abstract}

Assim, a utilização dos conceitos de diversidade e diferença nas escolas pode contribuir tanto para inclusão ou exclusão, dependendo das narrativas que serão contadas, do processo de construção e reprodução, pode sim definir o pertencimento e não pertencimento como também os que são "estrangeiros" e os que não são.

\title{
Cotidiano ESCOLAR: PRÁtICAS DOCENTES E A DIVERSIDADE E DIFERENÇA DOS ALUNOS MIGRANTES
}

Neste tópico, discutiremos sobre o cotidiano escolar das escolas de Educação Infantil e Ensino Fundamental, além das práticas docentes em relação à diversidade e à diferença.

Os discursos e representações que veiculam no cotidiano da escola constituem um aspecto inerente à sua cultura. Segundo Julia (2001, p. 2), a cultura escolar é permeada por "uma abordagem histórica, como sendo uma mescla de normas e práticas, aquelas 'que definem conhecimentos a ensinar e condutas a inculcar' e como um conjunto "que permite a transmissão desses conhecimentos e a incorporação de comportamentos". É pela cultura escolar que se formam os sujeitos sociais escolarizados, seus processos moldam, paulatinamente, o pensamento da sociedade. Assim, a maneira que vemos e percebemos o mundo, as pessoas que nos cercam, tudo isso é resultado da nossa formação cognitiva, ou seja, na escola, aprendemos e internalizamos os sentimentos racistas, homofóbicos, misóginos e xenófobos. É a partir dessa constatação que surgem as políticas educacionais que estabelecem diretrizes para trabalhar conteúdos que visam mudar essa percepção e proporcionar aprendizagens que respeitem e valorizem a diversidade humana.

Essa discussão, se acompanhada de práticas democráticas e científicas escolares, pode contribuir na diminuição da violência reportada a esse grupo em todos os ambientes sociais. Essas ações 
podem amortecer a misoginia, o machismo, o sexismo, o patriarcado, a LGBTQIAfobia, promovendo a equidade de gênero e diversidade sexual, a partir do exercício do convívio com as diversas características humanas, sociais, políticas, históricas, culturais (MAIO; OLIVEIRA; PEIXOTO, 2020, p. 63).

Alexandre (2019), ao observar as escolas de Educação Infantil, menciona que elas se ocupam do cuidar e educar com muitas atividades lúdicas. A rotina, geralmente, é composta por histórias infantis, brincadeiras, parques, brinquedos (gangorras, piscina de bolinha, escorregador, casinhas de plástico e de madeira), representações de histórias, ensaios para apresentações em eventos ou datas comemorativas consideradas importantes para a escola. As professoras fazem muitas dramatizações de histórias e teatros. Os clássicos da literatura infantil eram os preferidos, inclusive havia produção de roupas realizadas pelas próprias professoras que atuavam nas escolas. A prática de dramatização é interessante quando a própria criança representa, imita e, melhor ainda, cria suas histórias e suas narrativas. Entendemos que, dessa forma, elas têm uma experiência ativa e única, ao invés de somente assistir passivamente as professoras. A contação de história é uma atividade muito presente também. Para tanto, geralmente, os temas escolhidos são os clássicos da literatura ou obras com enredos infantis que pouco contemplavam a diversidade e a diferença das pessoas. No período de observação, aconteceu uma vez de uma das professoras contar uma história que tinha os personagens com perfil fenotípico diferente dos demais livros utilizados, era o livro Cama de mamãe (1998), de Joi Carlin. Essa história traz personagens que não têm a pele branca, possuem cabelos crespos, sendo composta pela mãe e os filhos somente, ou seja, rompe com o modelo tradicional de família que, geralmente, os livros mostram. No entanto, após terminar a história, os alunos foram levados para brincar no parque, a professora poderia ter realizado uma atividade de interpretação de texto ou mesmo propor a ilustração da história pelas crianças para que observassem a diversidade apresentada pelos personagens e pelo conteúdo.

As escolas do Ensino Fundamental ainda adotam práticas cotidianas centradas em cópias, memorização e repetição relacionadas à aprendizagem da linguagem, do raciocínio lógico matemático, além das demais áreas, sendo estas pouco enfocadas nas aulas. Havia uma valorização do silêncio, imobilidade e a obediência dos alunos, visando o controle do corpo. Os professores não trabalhavam os conteúdos dos livros didáticos e paradidáticos relativos à diversidade e à diferença, e os livros didáticos utilizados traziam crianças brancas e negras representadas em suas capas.

É importante mencionar que existem, atualmente, muitos livros disponíveis que abordam os temas voltados para a diversidade na escola e que devem ser explorados pelos professores, no entanto, o único dia em que o tema da diversidade e diferença foi contemplado nas aulas do Ensino Fundamental foi no dia 19 de abril, quando se comemora o dia do índio. Nesse dia, praticamente todas as crianças foram pintadas de índios e vestiram tangas. Na sala do $1^{\circ}$ ano, os alunos ensaiaram, durante uns quinze dias, uma música chamada indiozinho, mas a professora regente ficou doente no dia e a apresentação foi cancelada. A diretora teve que assumir a sala de aula, ela falou sobre a data, pediu para os alunos desenharem sobre o tema, fez observações interessantes 
ALEXANDRE, I. J.; VIEIRA, P. A. dos S.

sobre as condições das sociedades indígenas historicamente, sua cultura e modos de existências. Esse exemplo mostra que as atividades escolares podem ser realizadas pelas professoras por um viés estereotipado e ou de forma crítica e reflexiva. Arroyo (2012) disserta sobre a visão estereotipada que as escolas adotam em relação à diversidade e à diferença, utilizando a questão racial como exemplo:

[...] a visão negativa da cultura negra não é superada. A tendência tem sido descaracterizar essas culturas e reduzi-las a manifestações folclóricas e festivas, por vezes reduzi-las a instrumentos de controle e moralização da infância, adolescência e juventude negra. Tornouse frequente incluir os alunos considerados como problema em grupos de músicas, dança, capoeira [...] Como se tornou habitual abrir encontros de professores levando crianças negras e adolescentes negros para espetáculos de capoeira, rap, músicas, danças, coreografias. Nem sempre nos conteúdos das palestras, dos cursos e das oficinas sua cultura e seus saberes são objetos de reflexão, reconhecimento e respeito (ARROYO, 2010, p. 127).

As práticas pedagógicas nas escolas, na maioria das vezes, são tradicionais, não contemplam as teorias de aprendizagens sociocultural dos alunos. Isso ocorre porque o currículo ainda é eurocêntrico, se orienta por práticas pedagógicas que desconsideram as diferenças e, quando consideram, fazem de forma simplista, tipificada e desarticulada com as demais áreas do conhecimento. É possível os professores problematizarem as questões da diversidade e da diferença na escola, incorporando ao currículo conteúdos que promovam a inclusão de temas voltados para a diversidade étnica, racial, gênero, sexualidade e da cultura dos povos.

\section{POLÍTICAS DE INSERÇÃO E A AVALIAÇÃO ESCOLAR: AS PRÁTICAS DOS PROFESSORES EM RELAÇÃO OS ALUNOS MIGRANTES}

Neste tópico, focamos situações que envolveram o processo de adaptação dos alunos migrantes em uma nova escola, como são percebidas a diversidade e a diferença deles a partir do cotidiano escolar e como são as práticas de avaliação dos professores que recebem os alunos migrantes em suas salas.

No que se refere à adaptação dos alunos migrantes, eles têm que conviver com outros costumes, outra língua, outra cultura. Uma das primeiras necessidades para se adaptar é aprender a língua a portuguesa.

O impacto causado por essa nova realidade faz com que o imigrante de um modo geral, principalmente as crianças, se fechem. O que é natural, mas tem caráter negativo para a inserção, especialmente quando se quer aprender uma nova língua [...], as crianças em seus primeiros meses no Brasil se fecham por medo, vergonha, timidez, o que acaba impossibilitando um bom desenvolvimento escolar. As que já estão um pouco mais de tempo, por mais que ainda sintam muitas dificuldades se mostram mais desinibidas, participam das atividades escolares e ajudam os demais, já 
que podem se comunicar com mais facilidade - por meio da língua (SANTOS et al., 2015, s/n).

As crianças migrantes tendem a sentir vergonha de sua língua, de seus costumes, de suas experiências, além de interiorizem que a sua cultura é inferior, com menos valor. Com isso, eles passam a sofrer processos discriminatórios na escola (SILLER, 2011). Os alunos migrantes haitianos são percebidos como "diferentes", eles têm a pele negra e são de um país com índices elevados de pobreza. Além de tudo isso, esses alunos encontram no Brasil um histórico de racismo e uma realidade racista. Esse quadro é expresso em inúmeras notícias na mídia nacional, assim, a inserção e socialização de migrantes negros nas escolas brasileiras podem não ocorrer de forma cooperativa, solidária e afetuosa.

Os dados apresentados (ALEXANDRE, 2019; PETRUS et.al., 2016; ANDRÉ, 2016; COELHO, 2005) sobre o processo de escolarização de alunos migrantes negros mostram que eles são racializados ${ }^{4}$, e as escolas têm dificuldades para pensar políticas de acolhimento. Isso ocorre porque elas não estão preparadas para lidar com a diversidade e a diferença em seu espaço, e não é só por esse motivo que os professores podem ser racistas, é também porque esses temas são ausentes dos cursos de formação inicial e continuada.

Por outro lado, estudos (MACHADO, 2020; SANTOS et al, 2015) mostram que existem escolas com iniciativas didáticas para a inserção, socialização e suporte pedagógicos para os alunos migrantes através de projetos e ações que visam acolhimento deles e de suas famílias. Machado (2020, p.86) confirma que, nas indagações que fez aos professores de sua pesquisa sobre a inserção das crianças haitianas em uma escola pública em Blumenau, eles falaram que houve uma preocupação especial, por parte dos docentes, ao receber essas crianças, "mesmo que estes não estivessem preparados para esse fato" (REFERÊNCIA), e os professores desenvolveram projetos para amenizar o impacto da chegada deles nas escolas. Essa postura mostra que um olhar sensível sobre os alunos migrantes é fundamental quando não há uma proposta curricular, adesão de todos os professores e falta formação continuada sobre o tema.

Para melhorar a entrada dos alunos vindos de outros países nas escolas, desde 2012, o Estado de Mato Grosso, por meio da Secretaria de Educação do Estado (SEDUC), aprovou uma política pedagógica nas escolas estaduais que orienta os gestores e professores sobre como proceder na hora da avaliação para que eles não sejam prejudicados por serem migrantes e recém-chegados ao país. Para completar a formação educacional desses alunos, foi formada uma comissão para realizar diagnóstico e elaborar uma proposta pedagógica que atendesse, de maneira especifica, esse público. Conforme reportagem divulgada na página eletrônica do governo de Mato Grosso, a matriz curricular teria uma carga horária específica de língua portuguesa, que é o componente curricular que os haitianos mais têm dificuldades. E teriam atendimento com conteúdo pedagógico diferenciado com a ampliação de aulas de linguagens (ALEXANDRE, 2019).

A SEDUC também abriu processo seletivo em 2017 para Técnico de Atendimento Especial (TAE), que fosse haitiano e falasse a língua portuguesa para 
atender os migrantes do Haiti matriculados nas escolas do estado. Duas escolas em Sinop requisitaram vagas para a função, uma estadual de Ensino Fundamental e o Centro de Educação de Jovens e Adultos (CEJA). Apenas uma escola conseguiu o intérprete. Era uma moça e ela ficou por 10 dias trabalhando, pois foi dispensada pela escola. O motivo, segundo a secretaria da escola, foi porque era demasiada tímida e dormiu enquanto estava trabalhando com os alunos migrantes. Por isso, eles dispensaram essa intérprete e não contrataram outra pessoa para o lugar. Os alunos migrantes ficaram sem um tradutor que poderia ajudá-los a entender o conteúdo, além de ser um vínculo afetivo com sua terra de origem. Observamos, nesse caso, que a política educacional pode existir, mas o racismo institucional atuou de forma a prejudicar os alunos como também a moça haitiana. Esse tipo de racismo opera no Brasil, excluindo e marginalizando a população negra de seus direitos. Mostra também a intolerância e descaso da escola com os alunos migrantes, haja vista que a vaga não foi preenchida por má vontade da equipe da escola em não divulgar amplamente o edital para a comunidade e ter sido menos rigorosa e mais tolerante na avaliação da intérprete que foi dispensada (ALEXANDRE, 2019).

Sobre a formação continuada para os professores saberem atender os alunos migrantes, tanto os professores da rede estadual quanto da rede municipal informaram, em suas entrevistas, que não tiveram formação. Além disso, alguns sequer sabiam que teriam migrantes haitianos em suas salas. Assim, ficou a critério de cada professor aplicar e desenvolver ações para inserir os alunos migrantes, tais iniciativas não ocorreram nas salas observadas.

De acordo com Alexandre (2019), o sistema municipal de ensino de Sinop, em 2018, estabeleceu uma resolução para atender os direitos da criança migrante e refugiada a pedido do Conselho Municipal de Educação da cidade. Essa resolução determinava as normas de matrícula, transferência, aproveitamento, revalidação de estudos e outras providências para as crianças migrantes que estavam na Educação Infantil e no Ensino Fundamental (CONSELHO MUNICIPAL EDUCAÇÃO, 2018). A resolução assegura as garantias mínimas dos alunos aos estabelecimentos de ensino, no entanto, são necessárias as políticas de formação docente para os professores que atuam com os alunos migrantes. Enquanto isso não acontece, a aprendizagem desses alunos fica sob a responsabilidade deles mesmos e de suas famílias que se desdobram para ajudar os filhos.

Nas escolas, os alunos migrantes passam por avaliações dos professores constantemente, em dias específicos, além das avaliações externas, que servem para avaliar tanto as crianças quanto os professores, um exemplo é a provinha Brasil.

A provinha Brasil iniciou em 2008 e tem a intenção de fornecer respostas diretamente aos alfabetizadores e gestores da escola, ela foi criada pelo Instituto Nacional de Estudos e Pesquisas Educacionais Anísio Teixeira (Inep) a fim de diagnosticar o nível de alfabetização das crianças matriculadas no $2^{\circ}$ ano de escolarização das escolas públicas brasileiras (FREITAG et al., 2013, p. 393).

Essa provinha foi aplicada na turma do $2^{\circ}$ ano do Ensino Fundamental. $\mathrm{O}$ aluno migrante que estudava nessa sala teve dificuldades ao realizar a provinha porque ainda 
não dominava a leitura, as normas, as regras da língua portuguesa e os conceitos da cultura brasileira.

\begin{abstract}
A provinha Brasil foi aplicada na sala do $2^{a}$ ano pela coordenadora, que orientou a todos como teriam que responder as questões. Havia uma atividade com o desenho de uma Pêra. Os alunos teriam que escolher em qual alternativa estava escrita o nome da fruta (na hora de pintar todas as crianças brasileiras pintaram a Pêra de verde). $O$ aluno haitiano pintou metade de azul e metade de vermelho. Supus que ele não conhecia a fruta e assinalou a opção onde a escrita estava incorreta. A coordenadora se aproximou dele para ver como ele estava respondendo e percebeu o erro e disse:

- Leia aqui (apontando com o dedo sobre a palavra Pêra).

Eele leu corretamente:

- "Pera" (não pronunciou o acento circunflexo).

Depois ela pediu que ele relesse. Ela insistiu na releitura porque queria que ele percebesse que tinha feito o $X$ na resposta errada. Na verdade, ela não compreendeu porque ele não conhecia o que significava Pêra na língua portuguesa. Em criolo Pêra se escreve "Poire" mas soube ler certinha a palavra, juntos as letras, sílabas e leu duas vezes: PERA (Diário de campo, 09 jun. 2016).
\end{abstract}

Essa provinha, aplicada em todas as escolas do país, não considera a diversidade dos alunos, ela é destinada e pensada para as crianças brasileiras. É um instrumento que deveria ser adequado à língua do aluno migrante. Cristofolini (2012) estudou a edição da Provinha Brasil, em 2009, e constatou que essa provinha prioriza as dimensões linguística e cognitiva da leitura em relação à dimensão sociocultural da criança. A provinha aplicada é um instrumento avaliativo padronizado, com uma matriz de referência nacional que não contempla a diversidade sociocultural do país. Assim, o aluno migrante é desconsiderado nesse processo, e, quando avaliado, é de forma equivocada, haja vista que fala um outro idioma. Os responsáveis em produzir essas avaliações e os programas escolares estão distantes da realidade dos alunos de classe popular e dos alunos migrantes presentes nas escolas do país e que frequentam a escola pública.

Esse aluno do segundo ano lia as palavras, juntava as letras e sílabas, fazia relação fonema e grafema. Ele tinha certa dificuldade em produzir frases, por isso, as questões da provinha que continham frases para assinalar, ele não conseguia acertar. Considerando que fazia somente 7 meses que estava no Brasil, a situação era compreensível. Contudo, isso não quer dizer que não possuía conhecimentos, pois realizava as atividades, cálculos e lia bem.

Quando houve a avaliação bimestral no final do ano, a professora desse mesmo aluno foi considerada injusta pela coordenadora da escola, na opinião dela o aluno migrante não teria sido avaliado de forma correta:

-[...] eu fiquei naquela turma do segundo ano algumas vezes, daí percebi que ele era um menino muito esperto. [...] porque ele 
ALEXANDRE, I. J.; VIEIRA, P. A. dos S.

entendia tudo que eu falava em português. E é muito tranquilo. Algum tempo depois eu questionei a professora, quando ela colocou (na ficha de avaliação) tudo como se ele não tivesse capacidades consolidadas e nem desenvolvimento. Aí eu falei: -Espera aí (porque ao fazer o diagnóstico eu percebia que ele já escrevia, no nível alfabético e já lia. Muito embora ele na escrita, ainda usava algumas letras igual conforme no Haiti né; mas isto nos temos que ter esse olhar e considerar). - Aí eu fui e questionei: -Prof. porque isto aqui? (fez sinal mostrando a nota) -

Ela disse:

-Há! Mas é por isso..,e por isso.( a professora tentou argumentar).

Eu disse:

-Não professora! Olha meu diagnóstico aqui. Este menino já lê pequenos textos, já escreve ortograficamente, muito embora tem que ser trabalhado a ortografia, e a ortografia é numa fase mais avançado da alfabetização, escrevendo em português alfabeticamente, sem contar que eles são uns meninos fantásticos (Entrevista concedida pela coordenadora da escola, 05 dez. 2016).

Infelizmente, a avaliação tem sido vista por muitos professores como um momento de acertos de contas, de avaliar o comportamento e não a construção de saberes adquiridos ao longo do processo escolar. Além disso, muitas vezes, atrelado a essa percepção de avaliação, ainda existe o racismo, que pode influenciar na hora de avaliar o desempenho de alunos negros (CARVALHO, 2005; ALVES; SOARES, 2005). Alguns professores não concebiam que os alunos migrantes haitianos tinham habilidades cognitivas exemplares, um desempenho até melhor que as crianças brasileiras.

Com o aluno migrante, que estudava na $5^{\text {a }}$ serie, ocorreu da mesma forma. Ele teve excelente desempenho, e os professores comentavam sobre esse fato, ele aprendeu a falar proficientemente o português, tinha excelente raciocínio lógico matemático e outras habilidades cognitivas, mas, mesmo assim, a avaliação da professora de Geografia não foi condizente com o avanço que ela ressaltava dele.

No dia 10 de outubro de 2016 na aula de Geografia a professora iria aplicar uma prova, ela chegou e foi comentar sobre os conceitos dos alunos na última prova:

-Alguns alunos tiraram conceito B104 -, outros B+. Somente Nicete e Rai ficaram com $A$ (ambos eram brancos). - Vocês sabem que o aluno que tira $B$-é bom e aqueles que tiram $A$ são magníficos!

[...]. Após a revisão ela entregou as provas, que era de consulta. Ela foi perto do outro aluno haitiano, que recém tinha chegado ao Brasil e estava sala de Joel, para ver se ele estava conseguindo fazer a prova. Após, veio perto de mim e eu perguntei como tinha sido a avaliação de Joel ela disse que tinha sido boa, ele era B+. Perguntei a nota do outro menino haitiano, e ela disse que ficou com Btambém, mas que foi por orientação da SEDUC sobre os haitianos que chegaram no início do bimestre (Diário de campo, 10 dez. 2016). 
O conceito B é atribuído quando o estudante demonstra a compreensão básica "dos conceitos, procedimentos e atitudes trabalhados pelo professor em sala de aula, mas ainda não apresentar proficiência consolidada em consonância com os Objetivos de Aprendizagem" (ORIENTATIVO PEDAGÓGICO SEDUC, 2018, p. 28). Com base nesses critérios, o conceito a ele atribuído não foi consonante com os comentários elogiosos em relação ao potencial cognitivo desse aluno migrante haitiano.

Para Oliveira e Finco (2011), a escola, muitas vezes, orienta e reforça diferentes habilidades de acordo com o gênero e a raça, tem diferentes expectativas em relação ao desempenho intelectual de meninos e meninas, e com base nessas percepções estipula punições e méritos quando essas expectativas são satisfeitas.

Observamos, assim, que a abordagem em relação à diversidade e à diferença pode se configurar por práticas pedagógicas que tratam distintivamente os alunos segundo sua cor e origem. As escolas precisam rever essas práticas, sua forma de avaliação e buscar propostas escolares que se preocupam em receber bem os alunos migrantes, elaborar projetos e atividades que envolvam esses alunos, seus pais e a comunidade, pensando na qualidade do acolhimento, desempenho e sucesso escolar.

\section{CONSIDERAÇÕES FINAIS}

O objetivo deste texto foi discutir sobre a forma que os alunos migrantes haitianos são submetidos aos processos de avaliação escolar internos e externos, além das práticas cotidianas dos professores em relação aos alunos migrantes em duas escolas públicas do município de Sinop/MT.

Constatamos que os processos avaliativos são padronizados, pois não levam em conta a individualidade e diversidade cultural dos alunos. Esse tratamento incide sobre o desempenho e êxito escolar dos alunos migrantes, pelo fato das avaliações não considerar que eles vêm de um outro país, são de outra cultura, falam outra língua, e os professores não foram preparados para trabalhar com a diversidade desses alunos.

Observamos que as escolas colaboradoras mantêm práticas centradas em padrões normativos dominantes e não privilegia a diversidade e a diferença em seu currículo, que deve ser multicultural, intercultural e diverso. Só um currículo com essas características pode mobilizar e garantir a inserção e socialização de todos os alunos em sua diversidade, sejam eles migrantes ou não.

O enfoque curricular pensado a partir da diversidade humana pode vislumbrar uma educação que valoriza todos os modelos de seres humanos inseridos na escola e reconheça todos os conhecimentos como válidos. É preciso construir uma cultura escolar que incorpora diferentes epistemologias, especialmente dos povos excluídos e subalternizados.

Entendemos que os processos avaliativos, sejam eles preparados internamente ou externamente, devem considerar, no momento de elaboração e aplicação, a heterogeneidade dos alunos, somente assim os resultados poderão ser validados e indicativos para orientar as políticas de avaliação de forma abrangente, justa e igualitária para todos os alunos. 
ALEXANDRE, I. J.; VIEIRA, P. A. dos S

$\mathrm{Na}$ escola, os professores e toda equipe escolar necessitam de formação específica, voltada para temas como a diversidade e diferença. No caso dos povos migrantes, pensar políticas de acolhimento e a permanência deles, tendo como referenciais o cuidado, respeito e solidariedade.

Somente as práticas docentes que valorizam a diversidade e diferença poderão romper com os discursos racistas, misóginos, sexistas, homofóbicos e xenófobos na sociedade. Essas pautas são fundamentais e devem permear constantemente os debates nas instituições escolares e na sociedade, pois a atualidade tem nos mostrado que romper com os discursos de ódio e intolerância é emergente para as relações humanas e valorização da vida. Para isso, é urgente propor diálogos e reflexões sobre migração, infância, escola, diversidade e diferenças em diversos segmentos da sociedade.

Artigo recebido em: $18 / 03 / 2021$

Aprovado para publicação em: 28/05/2021

HAITIAN STUDENTS, THE SEARCH FOR AN (IM)POSSIBLE DREAM: THE REALITY LIVED BY MIGRANT CHILDREN IN SCHOOL EVALUATION

ABSTRACT: This text aims to discuss how Haitian students are subjected to internal and external school evaluation processes and teacher evaluation practices in two public schools in Sinop / MT. The data presented in this text are of an ethnographic approach and were generated from observations in the classroom, in the early grades of public schools that received Haitian migrant students in the period 2015-2016; and interview with the manager of one of the surveyed schools. We found that the evaluation processes are standardized and affect the performance and academic success of migrant students and that the teachers were not prepared to work with the diversity and difference, the knowledge and learning of these students.

KEYWORDS: Haitian Students. School Routine. School Evaluation.

ESTUDIANTES HAITIANOS, LA BÚSQUEDA DE UN (IM) POSIBLE SUEÑO: LA REALIDAD VIVIDA POR NIÑOS MIGRANTES EN LA EVALUACIÓN ESCOLAR

RESUMEN: Este texto tiene como objetivo discutir la forma en que los estudiantes haitianos son sometidos a procesos de evaluación escolar internos y externos y prácticas de evaluación docente en dos escuelas públicas de Sinop / MT. Los datos presentados en este texto son de enfoque etnográfico y fueron generados a partir de observaciones en el aula, en las clases de los primeros años de las escuelas públicas y que recibieron a estudiantes migrantes haitianos en el período 2015-2016; y entrevista con el director de una de las escuelas encuestadas. Encontramos que los procesos de evaluación están estandarizados y afectan el desempeño y éxito académico de los estudiantes migrantes y que los docentes no estaban preparados para trabajar con la diversidad y la diferencia, el conocimiento y el aprendizaje de estos estudiantes.

PALABRAS CLAVE: Estudiantes Haitianos. Vida Escolar. Evaluación Escolar. 
NOTAS

1 - O conceito de raça tratado nesse texto é no sentido sociológico do termo.

2 - Optamos pelo termo utilizado por Cogo e Souza (2013) em relação a Migrante e à migração, pois concordamos quando afirmam que remete à ênfase aos múltiplos aspectos que envolvem o movimento, trânsito, fluidez, as temporalidades e as motivações específicas das migrações contemporâneas e que são afetadas por questões políticas, econômicas e sociais.

3 - Pode ser acessado em:

https://repositorio.ufscar.br/handle/ufscar/11681?show=full\#: :text=S\%C3\%A30\%20essas\%20dif eren\%C3\%A7as\%20que\%20visibilizam,subalternizadas\%20em\%20rela\%C3\%A7\%C3\%A30\%20\%C 3\%A0s\%20demais. Acesso em: 09 de mar. de 2021.

4 - A ideia de "racialização" ou "formação de raça" se fundamenta em Silvério e Trinidad (2012), que defendem que raça não existe fora da representação social, sendo uma construção social e categoria não universal ou essencial da biologia.

\section{REFERÊNCIAS}

ABRAMOWICZ, A. et al. A diversidade e a diferença na educação. Contemporânea CIDADE, São Carlos, n. 2, jul/dez, 2011. p. 85-97.

ALEXANDRE, I. J. A presença das crianças migrantes haitianas nas escolas de SINOP/ MT: o que elas visibilizam da escola? 2019. Tese (Doutorado em Sociologia) - Programa de Pós-Graduação em Ciências Humanas, Universidade Federal de São Carlos, São Carlos, 2019.

ANDRÉ, B. P. Diversidade dos alunos estrangeiros e seu processo de adaptação em escolas brasileiras. In. BAHIA, J.; GOMES, C. Um olhar sobre as diferenças: a interface entre projetos educativos e migratórios [recurso eletrônico]. Organizadoras: Joana B.e Miriam S. - São Leopoldo: Oikos, 2016. p. 56 - 78.

ALTMANN, H. Orientação sexual nos Parâmetros Curriculares Nacionais. Estudos Feministas, São Paulo, Ano 9, 2001, p. 575-585. Disponível em https://www.scielo.br/pdf/ref/v9n2/8641.pdf. Acesso em: 09 de fev. de 2021.

ALVES, M. T. G.; SOARES, J. F. Cor do aluno e desempenho escolar: as evidências do Sistema de Avaliação do Ensino Básico - SAEB. XXVI- Encontro Anual as ANPOCS, Caxambu, 2002.

ARROYO, M. O direito a educação ameaçado: segregação e resistência. In. ARROYO, M.; ABRAMOWICZ, A. (Orgs.). A reconfiguração da escola: entre a negação e a afirmação de direitos. Campinas, SP: Papirus, 2009, p. 129-159. 
ALEXANDRE, I. J.; VIEIRA, P. A. dos S.

CANDAU, V. Direitos humanos, educação e interculturalidade: as tensões entre igualdade e diferença. Revista Brasileira de Educação, Rio de Janeiro, v. 13 n. 37 jan./abr. 2008, p. 45-185.

CARVALHO, M. Quem é negro, quem é branco: Desempenho escolar e classificação racial de alunos. Revista brasileira de educação, Rio de Janeiro, n.28, 2005, p.77-96.

COGO, D. M.; SOUZA, M. B. Guia das migrações transnacionais e diversidade cultural para comunicadores - Migrantes no Brasil. Bellaterra: Instituto Humanitas; Unisinos; Instituto de la Comunicación de la UAB, 2013. (Coleção: Guias de Diversidade Cultural Para Comunicadores).

CRISTOFOLINI, C. Refletindo sobre a Provinha Brasil a partir das dimensões sociocultural, linguística e cognitiva da leitura. Alfa: Revista de Linguística, São Paulo, v. 56, n. 1, 2012, p. 217-247.

FINCO, D.; OLIVEIRA, F. A sociologia da pequena infância e a diversidade de gênero e de raça nas instituições de educação infantil. In. A. L. G. Faria; D. Finco. (Orgs.), Sociologia da infância no Brasil. Campinas: Autores Associados. 2011, p. 55-80.

FREITAG, R. M. K et al.. Contribuições para o aprimoramento da Provinha Brasil enquanto instrumento diagnóstico do nível de alfabetização e letramento nas séries iniciais. Rev. bras. Estud. pedagog. (online), Brasília, v. 94, n. 237, maio/ago. 2013, p. 390-416. Disponível em: https://www.scielo.br/pdf/rbeped/v94n237/a04v94n237.pdf. Acesso em: 08 de fev. de 2021.

GOMES, N. L. Políticas públicas para a diversidade. Sapere aude, Belo Horizonte, v. 8, n. 15, Jan./jun. 2017, p. 7-22.

HALL, S. Que negro é esse na cultura Negra. In. HALL, S. Da diáspora: identidades e mediações culturais. Belo Horizonte: editora UFMG, 2003, p.335-349.

JULIA, D. A cultura escolar como objeto historiográfico. Tradução de Gizele de Souza. Revista Brasileira de História da Educação, São Paulo, n. 1, 2001, p. 9-44.

LIONCO, T.; DINIZ, D. Homofobia, silêncio e naturalização: por uma narrativa da diversidade sexual. Rev. psicol. polít. [online]., São Paulo, v.8, n.16, 2008, p. 307-324., p. 307-324. Disponível em: <https://url.gratis/aYailO>. Acesso em: 9 de fev. de 2021.

LOURO, G. L. Gênero e sexualidades: pedagogias contemporâneas. Pró-Posições, São Paulo, v.19, n.2, mai/ago, 2008, p.17-23.

MAIO, E. R.; OLIVEIRA, M.; PEIXOTO, R. Discussão sobre gênero nas escolas: Ações e resistências. Revista Retratos da Escola, Brasília, v. 14, n. 28, p. 57-74, jan./abr. 2020.

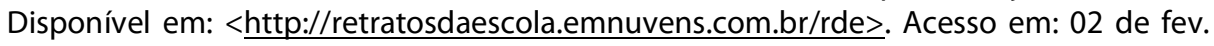
de 2020. 
MACHADO, R. S. Um encontro intercultural em contexto migratório: a inserção de crianças haitianas na educação infantil de Balneário Camboriú (SC/Brasil). 2020. Dissertação (Mestrado em Educação) - Universidade Regional de Blumenau, Blumenau, 2020.

PETRUS, et al. Filhos de refugiados congoleses no Rio de Janeiro: socialização e escolarização nas escolas da rede pública de ensino In. BAHIA, J.; GOMES, C. Um olhar sobre as diferenças: a interface entre projetos educativos e migratórios. [recurso eletrônico]. Organizadoras: Joana B. e Miriam S. - São Leopoldo: Oikos, 2016. p. 35-54.

MATO GROSSO. Secretaria de Estado e Educação. Avaliação por objetivos de aprendizagem - Orientativo pedagógico. Cuiabá: MT/SEDUC, 2018.

SANTOS, A. P. et. al. Inserção sociocultural de haitianos em Porto Velho: o ensino e aprendizado da língua portuguesa. Rev. Igarapé, Porto Velho (RO), v.1, n.5, 2-15, 2015, p. 43- 53.

SILLER, R.R. Infância, Educação Infantil, Migrações. 2011. 00f. Tese (Doutorado em Educação) - Universidade Estadual de Campinas, Campinas, 2011.

SILVA, T.T. Diferença e identidade: o currículo multiculturalista. In: SILVA, T. T. Documentos de identidade: uma introdução às teorias do currículo. 2. ed. $10^{\circ}$ reimp.Belo Horizonte, 2007, p.85-104.

SINOP. Secretaria Municipal de Educação. Prefeitura municipal de Sinop. Resolução ${ }^{\circ}$ 002/2018/CME. Disponível em: <https://url.gratis/4eVfkA>. Acesso em: 18 de dez. de 2018.

SILVÉRIO, V. R.; TRINIDAD, C. T. Há algo novo a se dizer sobre as relações raciais no Brasil contemporâneo? Revista Educação e Sociedade. Campinas, v. 33, n. 120, p. 891- 914, jul-set., 2012. Disponível: http://www.scielo.br/pdf/es/v33n120/13.pdf. Acesso: 08 de jan. de 2020.

WOODWARD, K. Identidade e diferença: uma introdução teórica e conceitual. In: SILVA, T. T..; HALL, S..; WOODWARD, K. (Orgs.). Identidade e diferença: a perspectiva dos estudos culturais. 15 ed. Petrópolis: Vozes, 2014, p. 7-72.

Ivone Jesus AlexAndre: Professora Adjunta na Área de Metodologia de Ensino na Universidade Estadual de Mato Grosso (UNEMAT) - Campus de Sinop MT. Doutora em Sociologia pela Universidade Federal de São Carlos (UFSCAR). Mestrado em Educação pela Universidade Federal de Mato Grosso (UFMT). Membro do Núcleo de 
ALEXANDRE, I. J.; VIEIRA, P. A. dos S

Educação, Gênero, Raça e Alteridade (NEGRA). Participa da Rede MT UBUNTU/Sinop.

Orcid: http://orcid.org/0000-0002-0200-7367

E-mail: jesusalexandre.ivone@gmail.com

Paulo Alberto dos Santos Vieira: Professor adjunto da Universidade do Estado de Mato Grosso. Coordenador da Rede mato-grossense de formação continuada para a educação das relações étnico-raciais (Rede MT Ubuntu). Líder do Grupo de pesquisa sobre ação afirmativa e temas da educação básica e superior (GRAFITE). Pesquisador associado ao NEGRA e ENCRESPAR, Neab's da Unemat nos Campi Universitários de Cáceres e Sinop respectivamente.

Orcid: https://orcid.org/0000-0003-1894-9954

E-mail: vieirapas@yahoo.com.br

Este periódico utiliza a licença Creative Commons Attribution 3.0, para periódicos de acesso aberto (Open Archives Initiative - OAI).

Inter-Ação, Goiânia, v.46, n.2, p. 679-695, maio/ago. 2021. Disponível em: <http://dx.doi.org/10.5216/ia.v46i2.68238>. 